\title{
Rendimento corporal e composição química de jundiás alimentados com diferentes níveis de proteína e energia na dieta, criados em tanques-rede
}

\section{Adilson Reidel ${ }^{1}$, Elizabeth Romagosa ${ }^{2}$, Aldi Feiden ${ }^{3}$, Wilson Rogério Boscolo ${ }^{3}$, Anderson Coldebella $^{1}$, Arcangelo Augusto Signor ${ }^{3}$}

\author{
1 IFPR, Paranaguá. \\ 2 Instituto de Pesca - APTA, SAA, SP. \\ 3 UNIOESTE - Campus Toledo, PR.
}

RESUMO - Objetivou-se analisar o rendimento corporal e a composição química de jundiás, Rhamdia quelen, alimentados com rações contendo diferentes níveis de proteína e energia e criados em sistema de tanques-rede. Utilizou-se a densidade inicial de 70 peixes $/ \mathrm{m}^{3}$, em 18 tanques-rede $\left(5,0 \mathrm{~m}^{3}\right)$, durante 324 dias. O delineamento experimental foi inteiramente casualizado com dois fatores - níveis de proteína bruta (PB), 25, 30 ou 35\%; e níveis de energia digestível (ED): 3.250 e 3.500 kcal - e três repetições. A dieta foi fornecida à vontade, mas mensurada diariamente. No início, um lote de peixes foi sacrificado para determinação dos parâmetros corporais e químicos. A cada 28 dias, dois peixes de cada unidade experimental foram abatidos para determinação dos comprimentos total e padrão, do peso total e dos pesos de fígado, gônadas, cabeça, tronco limpo e gordura visceral, respectivamente. Posteriormente, foram realizados cálculos dos índices hepatossomático e gonadossomático, da porcentagem de cabeça e do rendimento de carcaça e do rendimento de tronco limpo. A partir do mês de junho de 2006, também foram registrados o rendimento de filé e o sexo dos indivíduos. Para determinação da composição da carne do jundiá, foram realizadas as análises químicas de umidade, proteína bruta, lipídios e matéria mineral. O fornecimento da ração com 30\% de PB resultou em maior rendimento de tronco limpo. A composição do músculo não foi influenciada pelas dietas testadas. Os melhores resultados foram obtidos com a utilização de dietas contendo $30 \%$ de PB e $3.250 \mathrm{kcal}$ de energia digestível $/ \mathrm{kg}$.

Palavras-chave: análises químicas, bagre, rendimento corporal

\section{Catfish (jundia) body yield and chemical composition fed different protein and energy level in the diet, reared in net-tanks}

\begin{abstract}
The objective of this study was to analyze the body yield and the chemical composition of catfish (jundia), Rhamdia quelen, reared in net-tanks and fed with diets containing different levels of protein and energy. An initial density of $70 \mathrm{fish} / \mathrm{m}^{3}$, in 18 net-tanks $\left(5.0 \mathrm{~m}^{3}\right)$ was used, for 324 days. A randomized complete design was used, with two factors: Crude Protein (CP) at three levels, 25, 30 and 35\%; and Digestible energy (DE) at two levels, 3,250 and 3,500 kcal, and three replications. The diet was given freely, but it was measured daily. At the beginning of the experiment, one group of fish was killed to determine the body and chemical parameters. Every 28 days, two individuals of each experimental unit were killed and measured: total and standard length, total weight, liver, gonads, head, clean torso (CT) and visceral fat weight, respectively. Subsequently, the hepatosomatic index, gonadosomatic index, head percentage, carcass and clean torso yield were calculated. The fillet yield and the sex of the individuals were also registered from June/2006 on. Analyses of humidity, crude protein, lipids and mineral matter were conducted for the chemical composition of the jundia meat. Feed with $30 \%$ CP provided fish with better clean torso yield. The muscle composition was not influenced by the tested diets. The best result was obtained using diets containing 30\% CP and 3,250 kcal digestible energy/kg.
\end{abstract}

Key Words: body yield, catfishc, chemical analyses

\section{Introdução}

Uma espécie que vem despertando grande interesse para a piscicultura da Região Sul do Brasil, por seu crescimento acelerado, inclusive nos meses mais frios, é o jundiá, Rhamdia quelen (Carneiro et al., 2002). Stingelin et al.(1998), em revisão sistemática sobre o gênero Rhamdia, caracterizaram-no como peixe de couro, corpo alongado e crânio achatado, boca grande sem a presença de dentes com três pares de barbilhões sensitivos. A coloração do corpo varia de marrom-avermelhado-claro a cinza-escuro. É encontrado em diversos biótopos, habitando lagunas, poços e fundos de rios, com preferência a ambientes de águas calmas. 
Diferentemente de muitas espécies de peixes, o jundiá tem boa aceitação pelo mercado consumidor, pela carne saborosa e ausência de espinhas intramusculares (Lopes et al., 2006).

O conhecimento da composição corporal dos peixes é necessário para aumento de sua aceitação como alimento alternativo e para a competição com outras fontes proteicas largamente utilizadas, como as carnes bovina, suína e de aves (Bello \& Rivas, 1992; Freitas, 1988).

Sabe-se que a dieta pode influenciar a composição corporal dos peixes e que, se não atender às exigências da espécie ou resultar em baixa ingestão de nutrientes essenciais, pode ocasionar deposição de gordura visceral e corporal, bem como perda da qualidade da carne com elevada oxidação de ácidos graxos e, consequentemente, menor vida de prateleira (Proença \& Bittencourt, 1994; Chou \& Shiau, 1996; Hayashi et al., 2002).

Realizou-se este trabalho com os objetivos de avaliar o rendimento corpóreo e da composição química da carne de jundiás, Rhamdia quelen, alimentados com rações contendo três níveis proteicos (25; 30 e 35\% PB) e dois energéticos (3.250 e $3.500 \mathrm{kcal}$ de ED) e determinar a influência do período e do sexo dos animais criados em sistema intensivo (tanques-rede).

\section{Material e Métodos}

O trabalho foi realizado durante 324 dias (19/1/2006 a 8/12/2006) no reservatório da Hidroelétrica da Itaipu Binacional, município de Santa Helena/Paraná, localizada na área de transição do reservatório, junto ao Refúgio Biológico de Santa Helena. Utilizaram-se 18 tanques-rede dispostos em duas linhas paralelas, cada uma com nove tanques-rede de $5 \mathrm{~m}^{3}(1,70 \mathrm{~m} \times 1,70 \mathrm{~m} \times 2,00 \mathrm{~m})$, de modo que $0,25 \mathrm{~m}$ ficava suspenso na superfície da água, em decorrência da estrutura de flutuabilidade. A profundidade no local de instalação dos tanques foi de aproximadamente $8 \mathrm{~m}$ e o espaçamento entre uma linha e outra, de aproximadamente $20 \mathrm{~m}$, com $2 \mathrm{~m}$ entre os tanques-rede.

A espécie estudada foi o jundiá, Rhamdia quelen, e a densidade de estocagem foi de 70 peixes $/ \mathrm{m}^{3}$, com pesos e comprimentos iniciais médio de 47,39 $\pm 14,06 \mathrm{~g}$ e $17,21 \pm 1,75 \mathrm{~cm}$, respectivamente. Os peixes foram distribuídos em delineamento inteiramente casualizado com seis dietas, constituídas de três níveis de proteína bruta (PB) (25; 30 e 35\%) e dois níveis de energia digestível (ED) (3.250 e $3.500 \mathrm{kcal} / \mathrm{kg}$ ) (Tabela 1), isocálcicas e isofosfóricas, e três repetições.

As dietas foram fornecidas duas vezes ao dia, às 9 e 17 h, à vontade, e a quantidade fornecida mensurada diariamente. A cada 28 dias, foram realizadas biometrias para acompanhamento do crescimento; em cada biometria, foram capturados $10 \%$ dos peixes de cada tanque-rede e retirados dois peixes por unidade experimental, que foram acomodados em embalagens plásticas identificadas e munidos de oxigênio. Em seguida, os peixes foram transportados até o Laboratório de Tecnologia do Pescado da Universidade Estadual do Oeste do Paraná, Campus de Toledo, Paraná.

No laboratório, foram insensibilizados com gelo durante cinco minutos e, em seguida, medidos e pesados para obtenção dos comprimentos total e padrão, do peso total e dos pesos de fígado, gônadas, vísceras e cabeça para posterior cálculo dos índices hepatossomático e gonadossomático, da porcentagem de cabeça e dos rendimentos de carcaça e tronco limpo. A partir do mês de junho de 2006, também foram registrados os dados referentes ao rendimento de filé e ao sexo dos indivíduos, machos ou fêmeas. Para avaliação da composição química, foram realizadas análises químicas de umidade, lipídios, proteína bruta e matéria mineral com indivíduos no momento da instalação do experimento (janeiro de 2006), no mês de junho de 2006 e ao final do experimento (dezembro de 2006), segundo metodologia de AOAC (2005).

Para verificar os efeitos dos níveis de proteína bruta (PB) e energia digestível (ED) da ração, do sexo e do mês de cultivo nas características e rendimento de carcaça e nos índices químicos, com exceção do fator sexo, aplicou-se, separadamente, para cada um, a análise de variância multifatorial(ANOVA-multifatorial) (Gotelli \& Allison, 2004). Conforme sugerido por Box et al. (1978), as características analisadas foram submetidas à transformação ASen $\left(\mathrm{x}^{1 / 2}\right)$, pois são representadas em porcentagem.

Após ajuste do modelo fatorial completo, seguiu-se o protocolo "passo atrás" (Backward stepwise) de remoção de variáveis não-significativas $(\mathrm{P}>0,05)$ para obtenção do modelo final. Comparações múltiplas de médias foram realizadas para os fatores significativos utilizando-se o teste Tukey (Zar, 1999).

Os pressupostos dos modelos (resíduos $\sim N\left(0, \sigma^{2}\right)$ ) foram checados conforme descrito por Neter et al. (1990) e, para todos os testes, não foram rejeitadas $(\mathrm{P}>0,05)$ as hipóteses de homogeneidade de variância e normalidade nos resíduos. Todas as análises foram realizadas com auxílio do protocolo General Linear Models (GLM) do software Statistica 7.1 ${ }^{\circledR}$.

\section{Resultados e Discussão}

As análises de variância multifatorial aplicadas para os parâmetros analisados comprovaram influência 
Tabela 1 - Composição das rações experimentais, em porcentagem da matéria natural

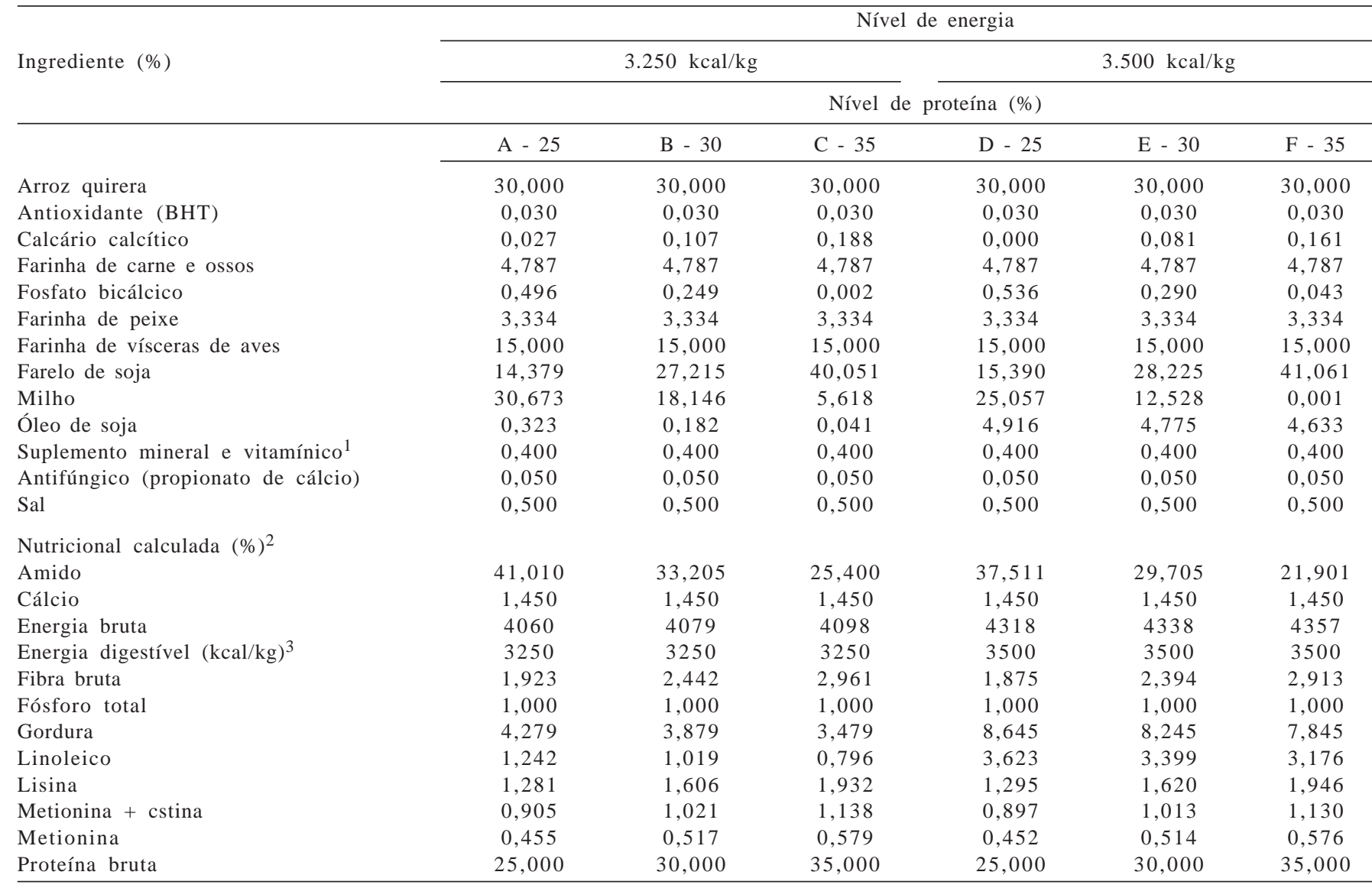

${ }^{1}$ Suplemento mineral e vitamínico (Vaccinar): metionina - 5\%; manganês - 3.750 mg; BHT - 0,5\%; cálcio - 43 g; Zn- 70 mg; ferro - 15.000 mg; cobre - 2.000 mg; cobalto - 50 mg; iodo - 125 mg; selênio - 0,2 mg; vit. A - 5.000 UI; vit. D3 - 300.000 UI/kg; vit. E - 80 mg; vit. K3 - 2.260 mg; vit. B1 - 2.500 mg; vit. B2 - 5.000 mg; vit. B6 - 2.500 mg; vit. B12 - $7.500 \mathrm{mg}$; vit. C - $75.000 \mathrm{mg}$; ácido fólico - $500 \mathrm{mg}$; ácido pantotênico - $12.500 \mathrm{mg}$; niacina - $20.000 \mathrm{mg}$; colina - $200.000 \mathrm{mg}$; lisina - $4 \%$; biotina - $150 \mathrm{mg} / \mathrm{kg}$.

${ }^{2}$ Valores da \% dos nutrientes propostos por Rostagno et al. (2005).

${ }^{3}$ Valores de energia digestível dos alimentos baseados em Boscolo et al. (2002) e Pezzato et al. (2002).

significativa dos níveis de PB sobre o índice hepatossomático e os percentuais de cabeça e tronco limpo. Os níveis de energia digestível, no entanto, influenciaram apenas o índice hepatossomático e o percentual de cabeça. Quando considerado na análise, o tempo influenciou todos os parâmetros analisados, enquanto o sexo dos peixes influenciou o índice gonadossomático, o rendimento de carcaça e o rendimento de filé. Nas interações entre fatores, somente a interação mês $\times$ sexo ocasionou diferença significativa no índice gonadossomático e no rendimento de carcaça.

Os valores do índice hepatossomático estão inversamente relacionados ao percentual de proteína bruta e à quantidade de energia contidas na ração, ou seja, quanto maiores os percentuais de PB e energia digestível na ração, menores os valores do índice hepatossomático (Figura 1). Durante os primeiros três meses de criação, esse parâmetro apresentou acréscimo, com posterior tendência inversa, ou seja, a proporção do índice hepatossomático em relação ao peso total diminuiu à medida que os indivíduos atingiram pesos e idades superiores (Figura 1). Essa tendência pode estar relacionada à quantidade de lipídios depositados no fígado durante os primeiros 90 dias, pois posteriormente os indivíduos iniciaram a maturação gonadal e essa reserva foi transferida, diminuindo os valores do índice hepatossomático.

Estatisticamente, a dieta não influenciou significativamente o índice gonadossomático nos peixes, mas houve efeito interativo entre sexo e tempo de produção, evidenciando que, a partir de abril, os valores desse índice aumentaram $(\mathrm{P}<0,05)$ para as fêmeas e esse aumento se manteve constante em setembro, outubro e dezembro de 2006 (Figura 2). O período de reprodução da espécie, segundo Da Silva et al. (2004), estende-se de agosto a março. Os maiores valores de índice gonadossomático para as fêmeas em comparação aos machos também foram descritos por Felin Jr. et al. (2007), que avaliaram exemplares de R. quelen criados em tanques-rede de pequeno volume, no entanto, os outros parâmetros analisados foram semelhantes entre ambos os sexos. 

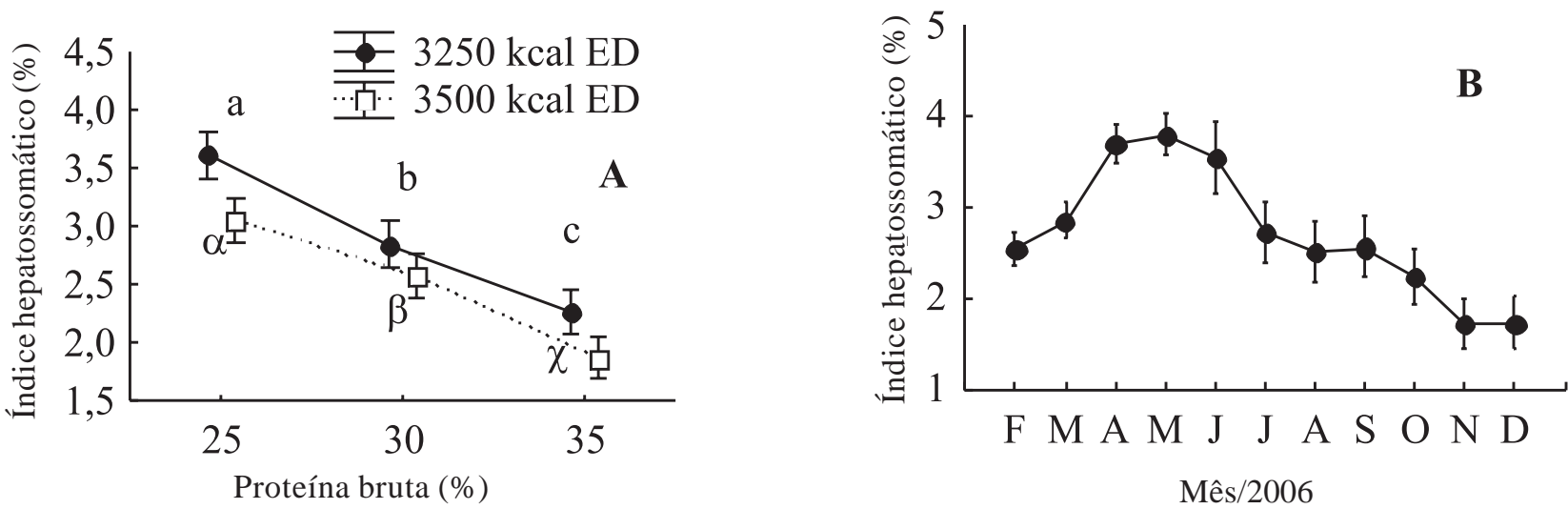

Letras e alfabetos distintos indicam diferenças significativas $(\mathrm{P}<0,05)$ pelo teste Tukey para os fatores proteína bruta e energia digestível, respectivamente.

Figura 1 - Índice hepatossomático em jundiás alimentados com dietas com diversos níveis de proteína bruta (A) em vários meses de criação (B).

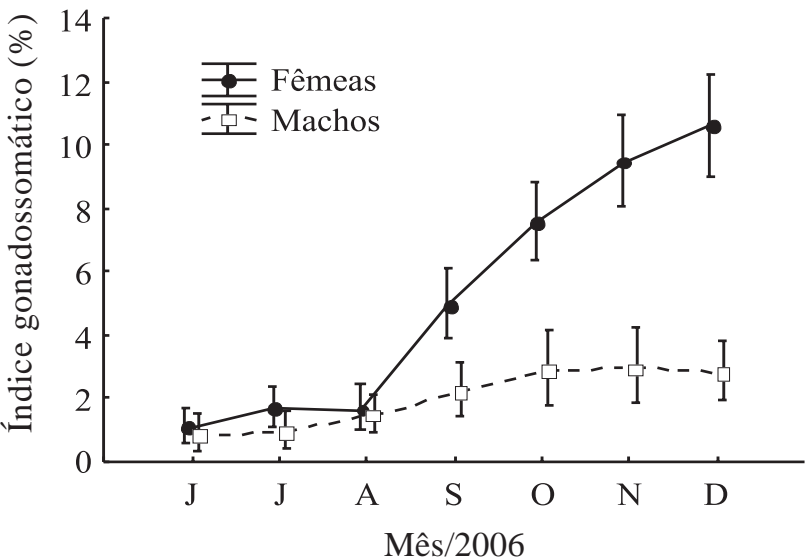

Figura 2 - Índice gonadossomático em fêmeas e machos de jundiás em diversos meses do ano.

O percentual de cabeça foi influenciado, tanto pelo nível de proteína bruta quanto pela energia e pelo tempo de criação, comportamento que parece estar diretamente relacionado ao tamanho dos indivíduos. O maior percentual de cabeça foi obtido com a ração contendo $25 \%$ de proteína bruta e variou de 15,5 a $16,5 \%$, superior aos valores observados nos níveis de 30 e 35\%, que não diferiram entre si (Figura 3). O melhor resultado foi obtido com $3.500 \mathrm{kcal}$ de energia metabolizável na ração (Figura 3), o que comprova que, quanto maior o indivíduo, menor sua cabeça, ou a porcentagem de cabeça. O percentual de cabeça diminuiu com o tempo de criação (Figura 3), comprovando a influência do tamanho dos indivíduos nessa característica. Pouey et al. (1999) obtiveram percentuais de cabeça de $20 \%$, maior que o encontrado neste trabalho. Entretanto, no decorrer do tempo, com o aumento no peso dos animais, os valores reduziram, com a mesma tendência encontrada neste estudo. A mesma relação - de que, quanto maior o indivíduo, menor o percentual de cabeça - foi observada por Souza \& Maranhão (2001) em tilápias-do-nilo (Oreochromis niloticus) em duas classes de peso.

O rendimento de carcaça obtido neste estudo variou de 78 a 87\% (Figura 4) e foi semelhante aos encontrados por Melo et al. (2002), que obtiveram valores entre 80,0 e $82,5 \%$ para peixes com peso médio de 40,0 e 45,0 g, respectivamente; e Carneiro et al. (2003), que obtiveram rendimento de carcaça de 80,0 a $87,5 \%$ em animais com pesos diferentes. Ressalta-se que, quanto maior os indivíduos, maior a tendência de altos rendimentos de carcaça, pois o percentual de cabeça reduz nos machos e diminui nas fêmeas, em decorrência da formação de gônadas, que aumentam no período de reprodução.

Neste estudo, os rendimentos de carcaça de jundiás foram inferiores aos apresentados por Reidel et al. (2004) para machos e fêmeas de curimbatá (médias de 91,26 e 89,40\%, respectivamente), porém superiores aos de tilápia, que, segundo Souza \& Maranhão (2001), variam de 75,61 a $78,18 \%$. Houve interação significativa entre o mês de criação*sexo para o rendimento de carcaça, com acentuadas diferenças entre machos e fêmeas no decorrer do tempo (Figura 4), devido ao aumento do volume das gônadas, ou seja, com a aproximação do período reprodutivo, os animais apresentaram pesos médios superiores, mas os valores de rendimento de carcaça reduziram. Esse mesmo resultado foi encontrado por Pouey et al. (1999), que avaliaram os principais componentes corporais do jundiá (Rhamdia sp.) e observaram que indivíduos maiores apresentavam rendimentos de carcaça significativamente menores $(\mathrm{P}<0,05)$ em comparação aos de menores pesos.

Os rendimentos de tronco limpo foram menores no nível de $25 \%$ de proteína bruta, porém não foram detectadas diferenças entre os níveis de 30 e 35\% (Figura 3C), o que 

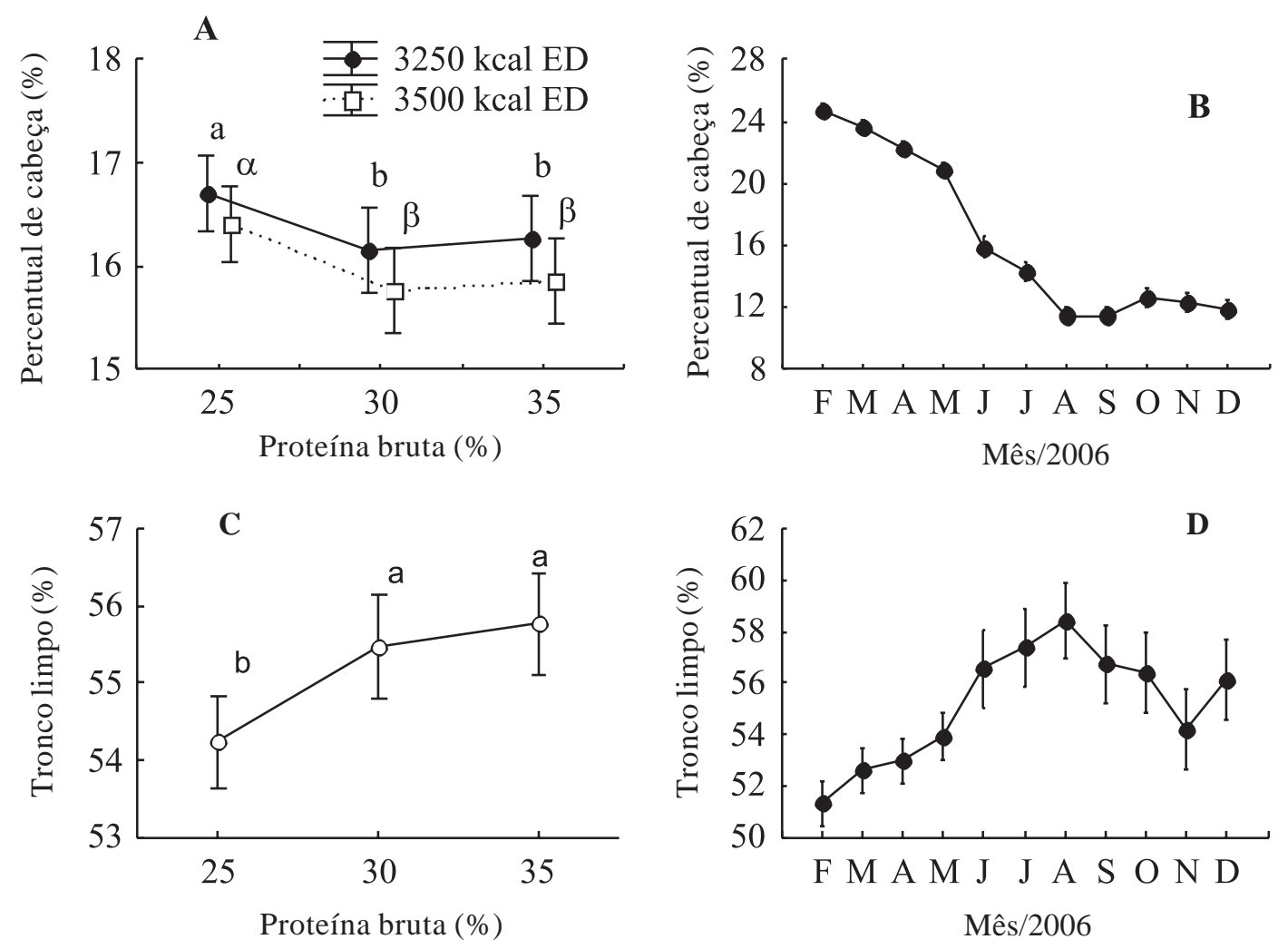

Letras e alfabetos distintos indicam diferenças significativas $(\mathrm{P}<0,05)$ pelo teste Tukey para os fatores: proteína bruta e energia digestível, respectivamente.

Figura 3 - Percentuais de cabeça e tronco limpo em jundiás alimentados com rações com três níveis de proteína bruta em diversos meses de avaliação.

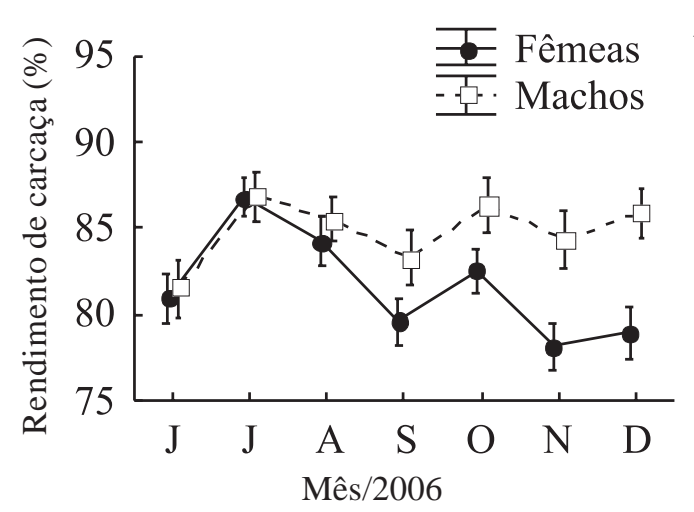

A

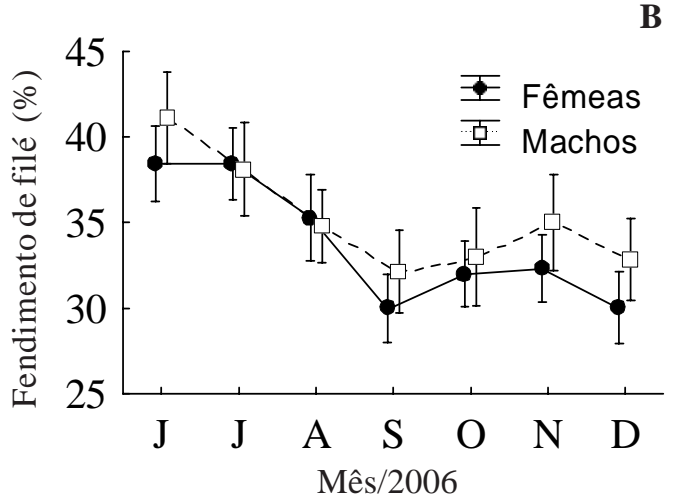

Figura 4 - Rendimentos de carcaça e filé de jundiás fêmeas e machos em diversos meses de avaliação.

pode estar relacionado também ao tamanho dos indivíduos e ao fato de que os peixes alimentados com os menores níveis de PB foram os que menos cresceram. Reidel et al. (2004) obtiveram rendimento de tronco limpo de 58,69 e 54,05\%, respectivamente, para machos e fêmeas de piauvuçu (Leporinus macrocephalus). Para o pacu (Piaractus mesopotamicus), Faria et al. (2003) observaram rendimento de tronco limpo de 54,8 a 60,3\%, entretanto Bencke et al.(2005) relataram valores de 56,24 a 58,73\%, dependendo da dieta utilizada no arraçoamento.
Boscolo et al. (2001) estudaram o rendimento de tilápia, linhagens tailandesa e comum, e observaram rendimentos de tronco limpo de 49,46\% e 51,39\%, respectivamente. Para a mesma espécie, Souza et al. (1999) observaram rendimentos tronco limpo de 56,43 a 53,46\% e relataram que essa diferença parece depender do tipo de corte da cabeça. Quando considerado o tempo de cultivo, os valores de tronco limpo tiveram aumento significativo até o mês de agosto, com posterior redução (Figura 3D), o que indica maior alocação de recursos para atividades reprodutivas. 
Os rendimentos de filé foram influenciados pelo sexo e pelo tempo experimental, mas não foram afetados pelas dietas testadas. Nas fêmeas, os rendimentos de filé foram relativamente inferiores aos dos machos, ao passo que, ao longo do tempo de criação, ambos os sexos apresentaram tendências decrescentes (Figura 4A), resultado possivelmente influenciado pelo ciclo de reprodução dos animais.

Os resultados obtidos neste estudo para o rendimento de filé estão de acordo com informações de Kubota \& Emanuelli (2004) de o rendimento de filé do jundiá, $R$. quelen, pode atingir até $42 \%$, mas pode variar com o tamanho dos peixes. O rendimento de filé do jundiá reduziu ao longo do tempo, devido à proximidade do período de reprodução - assim, suas gônadas aumentam de volume e o rendimento das partes corporais diminuem - ou ainda às diferenças no rendimento de filé, à forma de filetagem e à prática dos filetadores.

As espécies nativas em geral apresentam maior rendimento de filé em comparação à tilápia e, segundo Oliveira et al. (2001), o Prochilodus lineatus apresenta altos rendimentos de filé, cerca de $45 \%$. No entanto, essa espécie possui espinhas em Y na sua musculatura, o que diminui sua aceitação. Reidel et al. (2004) descreveram para machos e fêmeas de piavuçu (Leporinus macrocephalus) rendimento de filé de 44,30 e 40,48\%, respectivamente. Para o pacu (Piaractus mesopotamicus), o rendimento de filé variou de45,12 a 51,60\% (Faria etal., 2003; Boscolo etal., 2006).

Esses maiores rendimentos de filé descritos para espécies como curimbatá, piavuçu e pacu em relação à tilápia estão diretamente relacionados ao percentual da cabeça nesses peixes (Contreras-Guzmán, 1994).

As análises de variância multifatorial aplicadas para cada parâmetro químico apresentaram diferença significativa somente para a umidade para a variação do nível de energia digestível, enquanto a variável tempo (mês) apresentou variação significativa para todos os parâmetros analisados.

Assim, a umidade relativa não está relacionada à porcentagem de proteína bruta na ração, mas foi influenciada pelo tempo de experimentação $\left(F_{(2,55)}=31\right.$, $\mathrm{P}<0,0001)$ e pela quantidade de energia digestível $\left(\mathrm{F}_{(1,55)}=4,42, \mathrm{p}=0,04\right)$, de modo que, no tempo de criação, notou-se primeiro a redução neste parâmetro (junho/2006), seguida de pequena recuperação no mês de dezembro de 2006 (Figura 5A), de modo que o nível de $3.500 \mathrm{kcal}$ de energia digestível proporcionou aos indivíduos quantidades inferiores de umidade relativa e essa diferença não foi acentuada (Figura 5B).

As demais variáveis químicas avaliadas não foram influenciadas pelos níveis de proteína bruta nem pelos níveis de energia digestível na ração. No entanto, ao longo do tempo de criação, apresentaram comportamento inverso aos resultados obtidos para umidade relativa $\left(\mathrm{LP}: \mathrm{F}_{(2,53)}=353\right.$, $\mathrm{P}<0,0001$; PB: $\mathrm{F}_{(2,55)}=15, \mathrm{P}<0,0001 ; \mathrm{MN}: \mathrm{F}_{(2,55)}=30$, $\mathrm{P}<0,0001$; Figura 6)

Resultados similares aos observados neste trabalho foram reportados por Girao (2005), que observou 73\% de umidade, $13 \%$ de lipídios, 12,9\% de proteína bruta e 5,5\% de matéria mineral para o jundiá. Melo et al. (2003) avaliaram o efeito da alimentação na composição química da carcaça de jundiás e observaram 12,38 a 15,09\% de PB; 2,76 a 10,39\% de lipídios; 2,13 a 2,24\% de matéria mineral e 70,1 a 73,16\% de umidade.

Por outro lado, Maia et al. (1999) estudaram a composição química do Prochilodus cearencis em diferentes meses do ano e verificaram 74,9 a $78,5 \%$ de umidade, 17,8 a 19,6\% de proteína, 2,5 a 5,2\% de lipídios e 1,1 a 1,7\% de matéria mineral. Resultados próximos foram
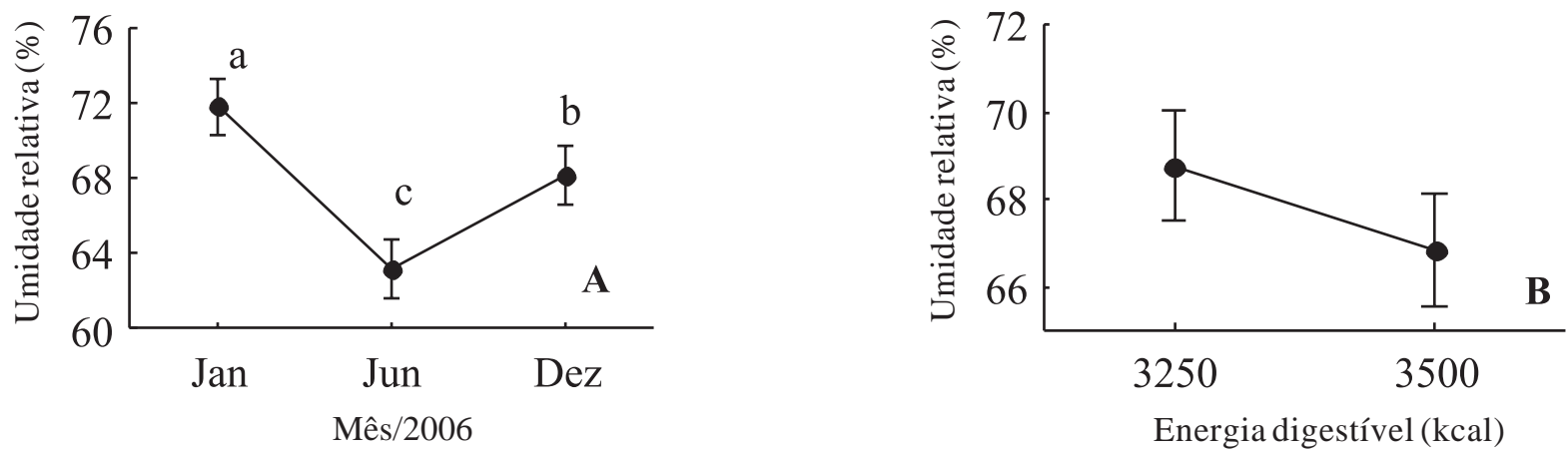

Letras distintas indicam diferenças significativas $(\mathrm{P}<0,05)$ pelo teste Tukey modificado (Zar, 1999).

Figura 5 - Umidade relativa em jundiás alimentados com rações com diversos níveis de energia digestível. 

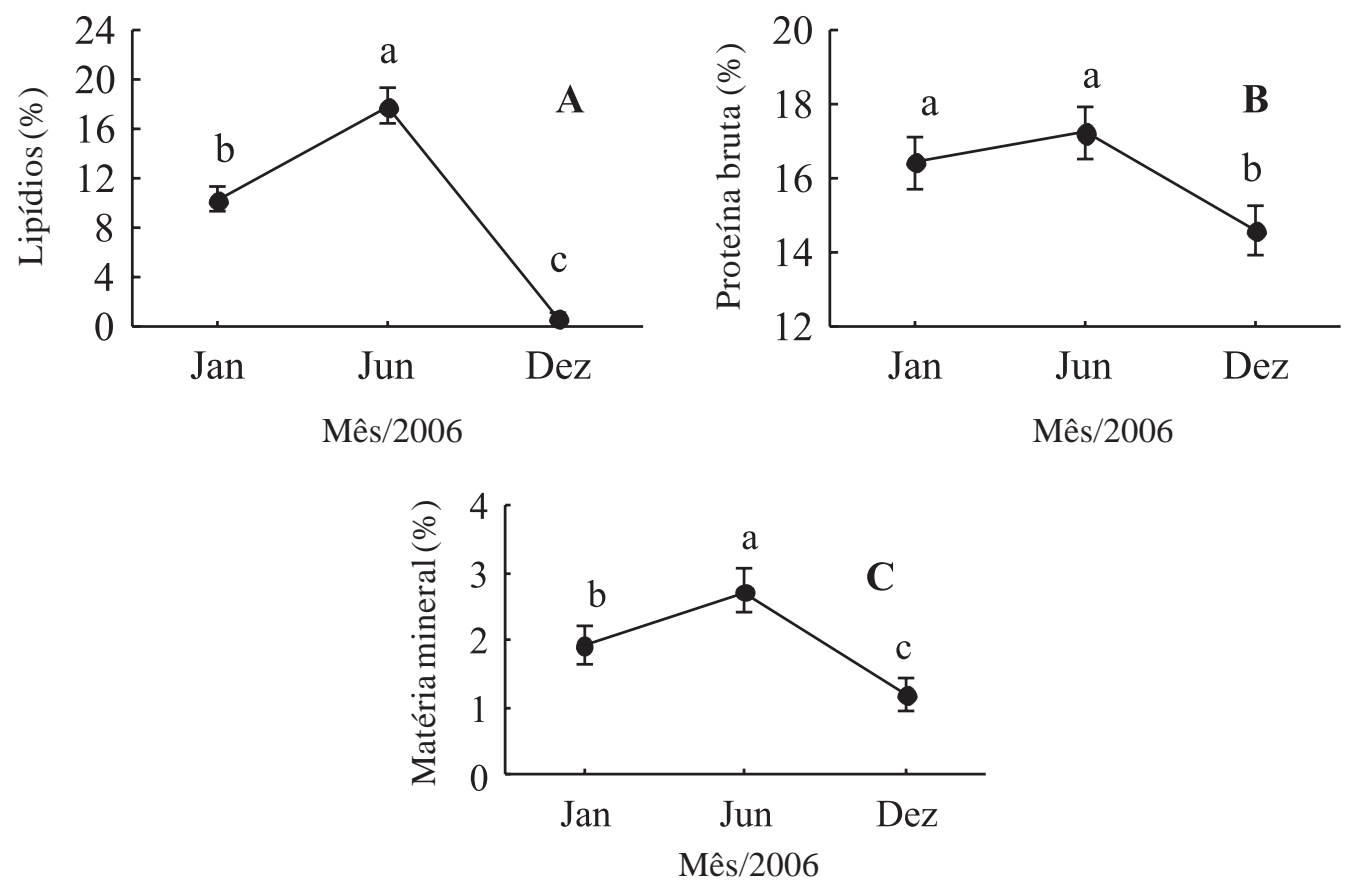

Letras distintas indicam diferenças significativas $(\mathrm{P}<0,05)$ pelo teste Tukey modificado (Zar, 1999).

Figura 6 - Porcentagens de lipídios, proteína bruta da carne e matéria mineral nos diferentes tempos de cultivo.

observados para o gênero Prochilodus e relatados por Maia et al. (1983), Maia (1990), Gurgel \& Freitas (1997) e Oliveira (1999) para proteína bruta, cujos valores foram entre 18,0 e 20,5\%. O teor de lipídios também foi semelhante, entre 0,5 e 4\%, para Prochilodus scrofa, P. cearensis e P. nigricans, aos relatados por Maia et al. (1983), Junk (1985) e Oliveira (1999). No entanto, valores superiores foram observados por Maia et al. (1994), de 6,0\% para o P. scrofa e, para o gênero Prochilodus, valores por estes autores foram inferiores aos encontrados para o jundiá, R. quelen.

Os teores de cinzas observados para os peixes de água doce foram de 1,9 a 2,5\%, inferiores aos encontrados por Gurgel \& Freitas (1997) e Kinsella et al. (1977) para Hoplias malabaricus, de 3,0 a 4,2\%. Santos et al. (2001) estudaram a composição química do filé de traíra e relataram que a porcentagem de umidade foi de $77,71 \%$; a de proteína bruta, 20,27\%; a de lipídios, 0,84\%; e a de matéria mineral, 1,39\% na matéria natural. À exceção dos teores de lipídios, os demais valores encontrados neste trabalho foram semelhantes.

\section{Conclusões}

Os melhores resultados foram obtidos com dietas contendo 30\% de proteína bruta e $3.250 \mathrm{kcal}$ de energia digestível/kg de ração.

\section{Referências}

ASSOCIATION OF OFFICIAL ANALYTICAL CHEMISTIS AOAC. Official methods of analysis of the AOAC. 18.ed. Gaithersburg: 2005. 658p.

BELLO, R.A.; RIVAS, W.G. Evaluación y aprovechamiento de la cachama, Colossoma macropomum cultivada, como fuente de alimento. Mexico: FAO, Proyecto Aquila II, 1992. 113p. (Documento de Campo, 2).

BENCKE, B; BOMBARDELLI, R.A.;SANCHES, E.A. et. al. Características morfométricas e rendimento de cortes da carne do pacu (Piaractus mesopotamicus) cultivado em tanquesrede no reservatório de Itaipú. In: CONGRESSO BRASILEIRO DE ENGENHARIA DE PESCA, 14., 2005, Fortaleza. Anais.. Fortaleza, 2005. p.1604-1618.

BOSCOLO, W.R.; HAYASHI, C.; SOARES, C.M. et. al. Desempenho e características de carcaça de machos revertidos de tilápias do Nilo (Oreochromis niloticus), linhagens tailandesa e comum, nas fases iniciais e de crescimento. Revista Brasileira de Zootecnia, v.30, n.5, p.1391-1396, 2001.

BOSCOLO, W.R.; HAYASHI, C.; MEURER, F. Digestibilidade aparente da energia e nutrientes de alimentos convencionais e alternativos para a tilápia do Nilo (Oreochromis niloticus, L.). Revista Brasileira de Zootecnia, v.13, n.2, p.539-545, 2002.

BOSCOLO, W.R.; REIDEL, A.; FEIDEN, A. et. al. Rendimento corporal do pacu (Piaractus mesopotamicus) cultivados em tanques-rede no reservatório de Itaipu, alimentados com diferentes níveis de proteína bruta In: SIMPÓSIO BRASILEIRO DE ENGEnHARIA DE PESCA, 1., 2006, Toledo. Anais.. Toledo, 2006. (CD-ROM).

BOX, G.E.P.; HUNTER, W.G.; HUNTER, J.S. Statistics for experimenters. An introduction to design, data analysis, and model building. New York: John Willey \& Sons, 1978. 653p.

CARNEIRO, P.; MIKOS, J.D.; BENDHACK, F. Processamento: o jundiá como matériaprima. Panorama da Aqüicultura, v.78, p.17-21, 2003. 
CARNEIRO, P.C.F.; BENDHACK, F.; MIKOS, J.D. et. al. Jundiá: um grande peixe para a região do sul. Panorama da Aqüicultura, v.12, n.69, p.41-46, 2002.

CHOU, B.S.; SHIAU, S.Y. Optimal dietary lipid level for growth of juvenile hybrid tilapia, Oreochromis niloticus x Oreochromis aureus. Aquaculture, v.143, n.2, p.185-195, 1996.

CONTRERAS-GUZMÁN, E. Bioquímica de pescados e derivados. Jaboticabal: FUNEP, 1994. 409p.

DA SILVA, L.V.F.; RADÜNZ NETO, J.; BALDISSEROTTO, B. Reprodução. In: BALIDSSEROTTO, B.; RADÜNZ NETO, J. (Eds.). Criação de jundiá. Santa Maria: Editora UFSM, 2004. p.117-141.

FARIA, R.H.S.; SOUZA, M.L.R.; WAGNER, P.M. et. al. Rendimento do processamento da tilápia do Nilo (Oreochromis niloticus Linnaeus, 1757) e do pacu (Piaractus mesopotamicus Holmberg, 1887). Acta Scientiarum, v.25, n.1, p.21-24, 2003.

FELIN JR., R.; COLDEBELLA, I.J.; MANFIO, M.L. Avaliação de machos e fêmeas de Rhamdia quelen criados em tanques-rede de pequeno volume. In: WORKSHOP SOBRE JUNDIÁ, 2007, Santa Maria. Anais... Santa Maria, 2007. p.41.

FREITAS, J.V. Estudo de algumas características físicas e da composição química da carpa espelho, Cyprinus carpio (L. 1758), criada em cativeiro. Fortaleza: DNOCS, 1988. p.5-15. (Boletim Técnico, 46).

GIRÃO, P.M. Exigência em lisina e estimativa dos aminoácidos essenciais com base no conceito de proteína ideal para alevinos de jundiá, Rhamdia quelen. 2005. 30f. Dissertação (Mestrado em Aqüicultura) - Universidade Federal de Santa Catarina, Santa Catarina.

GOtelli, N.J.; ALLison, A.M. A primer of ecological statistics. Sunderland: Sinauer Press, 2004. 510p.

GURGEL, J.J.S.; FREITAS, J.V.F. Variação estacional do teor de gordura da curimatã comum, Prochilodus cearensis Steindachner, pescada do piauí, Plagioscion squamosissimus (Heckel) e traíra, Hoplias malabaricus (Bloch) no açude Orós, em Orós, Ceará. Fortaleza: DNOCS, 1997. p.149163. (Boletim Técnico, 35).

HAYASHI, C.; BOSCOLO, W.R.; SOARES, C.M. et. al. Exigência de proteína digestível para larvas de tilápia do Nilo (Oreochromis niloticus) no período de reversão sexual. Revista Brasileira de Zootecnia, v.31, n.2, p.823-828, 2002.

JUNK, W.J. Temporary fat storage an adaptation of some fish species to the waterlevel fluctuation and related environmental changes of the amazon river. Revista Amazoniana, v.9, n.3, p.315-351, 1985.

KINSELLA, J.E.; SHIMP, J.L.; MAI, J. et. al. Sterol, phospholipid, mineral content and proximate composition of fillets of select freshwater fish species. Journal of Food Biochemistry, v.1, n.2, p.131-140, 1977

KUBOTA, E.H.; EMANUELLI, T. Processamento do pescado. In: BALIDSSEROTTO, B.; RADÜNZ NETO, J. (Eds.) Criação de jundiá. Santa Maria: Editora UFSM, 2004. p.117-141.

LOPES, P.R.S.; POUEY, J.L.O.F.; ENKE, D.B.S. et al. Desempenho de alevinos de jundiá Rhamdia quelen alimentados com diferentes níveis de energia na dieta. Revista Biodiversidade Pampeana, v.4, n.13, p.32-37, 2006.

MAIA, E.L. Otimização da metodologia para a caracterização de constituintes lipídicos e determinação da composição em ácidos graxos e aminoácidos de peixes de água doce. 1990. 242f. Tese (Doutorado em Ciência e Tecnologia de Alimentos) - FEA/UNICAMP, Campinas.

MAIA, E.L.; RODRIGUEZ-AMAYA, D.B.; AMAYA-FARFÁN, J. Proximate, fatty acid and amino acid composition of the Brazilian freshwater fish Prochilodus scrofa. Food Chemistry, v.12, p.275-286, 1983a.

MAIA, E.L.; RODRIGUEZ-AMAYA, D.B.; FRANCO, M.R.B. Fatty acids of the total, neutral and phospholipids of the Brazilian freshwater fish Prochilodus scrofa. Journal of Food Composition and Analysis, v.7, p.240-251, 1994.

MAIA, E.L.; OLIVEIRA, C.C.S.; SANTIAGO, A.P. et al. Composição química e classes de lipídios em peixe de água doce curimatã comum, Prochilodus cearensis. Ciência e Tecnologia de Alimentos, v.19, n.3, p.433-437, 1999.

MELO, J.F.B.; BOIJINK, C.L.; RADÜNZ NETO, J. Efeito da alimentação na composição química da carcaça do jundiá Rhamdia quelen. Revista Biodiversidade Pampeana, v.1, n.1, p.12-23, 2003.

MELO, J.F.B.; RADÜNZ NETO, J.; SILVA, J.H.S. et. al Desenvolvimento e composição corporal de alevinos de jundiá (Rhamdia quelen) alimentados com dietas contendo diferentes fontes de lipídios. Ciência Rural, v.32, n.2, p.323-327, 2002.

NETER, J.; WASSERMAN, W.; KUTNER, M.H. Applied linear statistical models. 3.ed. Illinois: 1990. 52p.

OLIVEIRA, L.G.; PIANA, P.A.; LEMAINSKI, D. et. al. Avaliação da carcaça e características morfométricas do curimbatá Prochilodus lineatus, e piavuçu Leporinus macrochephalus machos e fêmeas. In: CONGRESSO BRASILEIRO DE ENGENHARIA DE PESCA, 12., 2001, Foz do Iguaçu. Anais... Foz do Iguaçu: CONBEP, 2001. 8p.

OLIVEIRA, S.L.C.L. Estudo dos constituintes lipídicos em peixes do Ceará. 1999. 118f. Dissertação (Mestrado em Ciência e Tecnologia de Alimentos) - Universidade Federal do Ceará, Fortaleza.

PEZZATO, L.E.; MIRANDA, E.C.; BARROS, M.M. et. al. Digestibilidade aparente de ingredientes pela tilápia do Nilo (Oreochromis niloticus). Revista Brasileira de Zootecnia, v.31, n.4, p.1595-1604, 2002.

POUEY, J.L.O.F; MIOTTO, H.C.; KUNZ, T.L. et. al. Principais componentes corporais do jundiá Rhamdia sp cultivado na densidade de um peixe $/ \mathrm{m}^{2}$ e dividido em quatro faixas de peso. Anais... In: REUNIÃO ANUAL DA SOCIEDADE BRASILEIRA DE ZootecniA, 36., 1999, Porto Alegre. Anais... Porto Alegre: Sociedade Brasileira de Zootecnia, 1999. p.314.

PROENÇA, C.E.M.; BITTENCOURT, P.R.L. Manual de piscicultura tropical. Brasília: IBAMA, 1994. 196p.

REIDEL, A.; OLIVEIRA, L.G.; PIANA, P.A. et. al. Avaliação de rendimento e características morfometricas do curimbatá Prochilodus lineatus (VALENCIENNES, 1836), e do piavuçu Leporinus macrochephalus (GARAVELLO \& BRITSKI, 1988) machos e fêmeas. Revista Varia Scientia, v.4, n.8, p.71-78, 2004.

ROSTAGNO, H.S.; ALBINO, L.F.T.; DONZELE, J.L. et. al. Tabelas brasileiras para aves e suínos - Composição dos alimentos e exigências nutricionais. 2.ed. Viçosa, MG: 2005. $141 \mathrm{p}$.

SANTOS, A.B.; MELO, J.F.B.; LOPES, P.R.S. et. al. Composição química e rendimento do filé da traíra (Hoplias malabaricus) Revista da Faculdade de Zootecnia, Veterinária e Agronomia, v.7/8, n.1, p.33-39, 2001.

SOUZA, M.L.R.; MACEDO-VIEGAS, E.M.; KRONKA, E.N. Influência do método de filetagem e categorias de peso sobre rendimento de carcaça, filé e pele da tilápia do Nilo (Oreochromis niloticus). Revista Brasileira de Zootecnia, v.28, n.1, p.1-6, 1999.

SOUZA, M.L.R.; MARANHÃO, T.C.F. Rendimento de carcaça, filé e subprodutos da filetagem da tilápia do Nilo, Oreochromis niloticus (L), em função do peso corporal. Acta Scientiarum, v.23, n.4, p.897-901, 2001

STINGELIN, L.A.; MIOTTO, H.C.; POUEY, J.L.O. Rendimento de carcaça e carne do jundiá (Rhamdia sp) na faixa de 300 $400 \mathrm{~g}$ de peso total cultivado na densidade de 1 peixe $/ \mathrm{m}^{2}$. In: CONGRESSO DE INICIAÇÃO CIENTÍFICA, 7., 1998, Pelotas. Anais... Pelotas: UfPEL/UCPEL/FURG, 1998. p.332.

ZAR, J.H. Biostatistical analysis. 4.ed. New Jersey: Prentice Hall, 1999. 663p. 